\title{
A la conquista de la leyenda negra: imperio, cosmopolitismo y el culto del yo en Dulce dueño
}

\author{
Álvaro A. Ayo \\ (UNIVERSIDAD DE TENNESSEE, KNOXVILLE) \\ aayo@utk.edu
}

(recibido setembro/2018, aceptado novembro/2018)

RESUMEN: En este estudio se arguye que en los lustros previos a la Primera Guerra Mundial Pardo Bazán cuestiona la negativa evaluación de la historia de España, especialmente de su empresa imperial en el Nuevo Mundo, conocida con el término "leyenda negra", siendo una de las primeras personas en usarlo. Pero en vez de tratar de exonerar a su país incurriendo en el patrioterismo de la "leyenda dorada" socava la presunta superioridad cultural y moral de sus detractores en las principales potencias europeas de la era moderna. Si el desastre de 1898 parece ratificar la condición periférica y rezagada de España ante Europa, la Gran Guerra pondrá en evidencia el lado oscuro de la civilización occidental que Pardo discierne años antes. En Dulce dueño, se vale de una estrategia narrativa cimentada en la densidad intertextual a fin de impugnar las pretensiones de centralidad espacial y de teleológica supremacía histórica que los imperios occidentales utilizan para justificar su dominio global y la exclusión de España. Involucrada en varias situaciones hiperbólica e irónicamente delineadas que suceden durante sus viajes por España y Europa, la protagonista y narradora de la novela conquista el orbe y luego fraterniza con la humanidad mediante un abrazo cosmopolita. Además, su aversión al prosaísmo del mundo moderno la lleva a desarrollar una personalidad egocéntrica que se manifiesta en el culto de su yo. Su historia, empero, no ofrece respuestas reivindicatorias ni para las naciones ni para sus ciudadanos (particularmente para las mujeres), prueba del intrincado novelar y de la mirada profundamente crítica de Pardo Bazán.

PALABRAS CLAVE: Emilia Pardo Bazán, Dulce dueño, imperio, cosmopolitismo, culto del yo.

ABSTRACT: In this study it is argued that in the years leading up to World War I Pardo Bazán questioned the negative view of Spain's history, chiefly its imperialist endeavors in the New World, that came to be known as the "black legend" - she was one of the first to use the term. But instead of trying to exonerate her country through the jingoistic platitudes of the "golden legend," Pardo undermined the supposed cultural and moral superiority of its detractors in the main European imperial powerbrokers of the modern era. While the 1898 disaster seemed to ratify Spain's peripheral and straggling position vis-à-vis the rest of Europe, the Great War unveiled the dark side of Western civilization that Pardo identified years earlier. In Dulce dueño, Pardo uses a narrative strategy based on intertextual density to challenge claims of spatial centrality and teleologically concocted historical supremacy deployed by Western empires to justify their global dominance and Spain's exclusion. Involved in several hyperbolically and ironically delineated situations that occur during her travels through Spain and Europe, the novel's protagonist and narrator conquers the globe and later fraternizes with the whole of humanity 
through a cosmopolitan embrace. Furthermore, her aversion to the prosaic in the modern world leads her to develop an egocentric personality that manifests itself in a veritable cult of the self. Her story, however, does not offer edifying answers for nations or individuals (particularly for women), which evinces Pardo's intricate fiction and profoundly critical worldview.

KEY WORDS: Emilia Pardo Bazán, Dulce dueño, empire, cosmopolitanism, cult of the self.

No hay hecho, por humilde que sea, que no implique la historia universal (Borges, El Aleph 115).

De las dos sangres excelentes, la del martirio y la de la guerra (Dulce dueño, II 1021).

Como han indicado muchos entendidos, prestarle atención a lo que Emilia Pardo Bazán denomina el "elemento religioso" es importante para apreciar Dulce dueño (1895: 9) ${ }^{1}$. Sin embargo, en esta novela que publica en 1911 dicho elemento se supedita a un ecléctico complejo de temas intelectuales, políticos, literarios y estéticos de su interés a la sazón. La trama, relatada casi íntegramente en forma autobiográfica, presenta a Lina Mascareñas. Ella es una mujer española y europea que, especialmente tras heredar una fortuna que le otorga cierto grado de independencia, debe negociar relaciones afectivas y de poder en ámbitos privados y públicos mientras viaja por España y otros países del Viejo Continente durante la Era del Imperio (1875-1914). Mediante Lina, encarnación de múltiples figuras literario-culturales y de nociones estéticas e intelectuales, la polímata gallega reflexiona irónica e hiperbólicamente en torno a las conexiones entre el individuo, la nación y la esfera supranacional -cosmopolita e imperial o posimperial- en el mundo moderno ${ }^{2}$.

Más específicamente, en esta su última novela Pardo Bazán explora a través de un personaje femenino tanto la conflictiva situación de España en y ante la modernidad como la condición social y sicológica del individuo problematizando los modelos dominantes de masculinidad y feminidad, los de identidad nacional y continental y los de salud mental y racionalismo (1901: 62-63). Sus apreciaciones del impacto global de Occidente y del prosaísmo de la vida crecientemente secular en el mundo moderno que articula en Dulce dueño constituyen un producto y el reflejo del período comprendido entre la conflagración hispano-estadounidense de 1898 y la Primera Guerra Mundial. Numerosos escritos coevos complementan estas apreciaciones. Sobresalen sus meditaciones en torno a las Ilamadas "leyenda negra" y "leyenda dorada" que sopesa en La España de ayer y la de hoy (1899) (1901: 62-63)

Evitando el españolismo exculpatorio y conservador que vertebra la leyenda dorada, Pardo cuestiona la superioridad moral, cultural e histórica de los países europeos de donde provienen las acusaciones que conforman la leyenda negra, es decir, la tendenciosa evaluación de la historia de España, máxime de su participación en la conquista del Nuevo Mundo, que ratifica su atraso (concepto temporal) y la confina a la periferia (concepto espacial) de Occidente. Según esta evaluación iniciada siglos antes España es una nación 
anómala, lo cual se manifiesta primordialmente en la brutalidad de su empresa imperialista y en la incapacidad de sus ciudadanos para encajar en el mundo moderno (1901:79, 83). Sabedora del alcance global de estas reflexiones la condesa también concibe, con marcado escepticismo, una alternativa de hermandad universal al ímpetu de conquista de aquellos años no muy distinto al de los siglos XVI y XVII. Es un ímpetu que desvela el lado oscuro de la civilización occidental a la cual, para bien y para mal, pertenece España y de la que Pardo se considera entusiástica y crítica partícipe.

Como se verá, la inclusión en Dulce dueño de un denso complejo de textos (obras específicas, sistemas discursivos) e imágenes (personajes ficticios e históricos, íconos culturales) de distintas épocas y lugares que en su mayoría confluyen incómodamente en Lina es la estrategia narrativa que emplea Pardo Bazán para representar su época. Lo que pretende por medio de esta confluencia es poner en tela de juicio las diferencias espaciotemporales entre su país y el resto de Occidente, pero sin caer en el inmovilismo relativizador y escapista que esta representación palimpséstica puede suscitar (Pardo, 1961: 62). Vale decir, trastoca las representaciones convencionales de espacialidad (ubicación, distancia, tamaño) y de temporalidad (diacronía, progreso, regresión, la distinción tajante entre premodernidad y modernidad) sin descartar mapas y calendarios ${ }^{4}$. Esta labor revela una postura de autoconfianza no exenta de autocrítica, más sólida conforme avanza el siglo XX, que contrasta con la persistente evaluación negativa y hasta fatalista del país por parte de muchos de sus contemporáneos basada en la polarización España-Europa, sobre todo tras el "tan melodramáticamente Ilamado 'Desastre"” (Blanco, 2012: 19). El desarrollo de la compleja postura de Pardo, a su vez, demuestra la variedad de reacciones que desata este evento y lo duradero de su impacto en la sicología nacional ${ }^{5}$.

Tres inusitadas escenas en la autobiografía de Lina informan esta discusión. En realidad, lo extremo de los lugares y las circunstancias en que Pardo coloca a su protagonista complementa su estrategia palimpséstica. La primera es la muerte de uno de los pretendientes de la autobiógrafa durante una tempestad en un lago suizo que conquista la atención mundial gracias a que las agencias internacionales de noticias difunden la trágica historia de unos amantes españoles que supone una fantasía épica e imperialista tristemente irónica en la España pos-98 y en las postrimerías de la edad dorada de los imperios europeos (1964: II 1012-1013). El hecho de que Lina sobrevive la tempestad equivale a una victoria personal y nacional luego de lidiar, mayormente en calidad de doncella andante e infatigable esteta, con varios hombres (mentores y pretendientes/caballeros andantes) que intentan controlarla. La segunda gira en torno al hiperbólico abrazo a la humanidad, o la aceptación afectiva universal, que Lina efectúa al cuidar abnegadamente de una chiquilla sobremanera enferma en un insignificante rincón de España (1964: II 1023). Supera así su aversión al trato social y a lo tedioso y lo grotesco de la vida moderna en pos de un cosmopolitismo humanitario que quizás la redima.

\footnotetext{
${ }^{4}$ Esta discusión es de gran interés para Pardo desde joven. En "Reflexiones científicas sobre el darwinismo" (1877), socava nociones unilineales de representación temporal con sutiles implicaciones espaciales al controvertir la aplicación del evolucionismo a la historia de las civilizaciones humanas realzando los paralelismos y las rupturas en vez de la continuidad y el progreso (3: 561, 566). También critica el "orgullo con que el europeo mide a todos por su nivel” (3: 562).
} 
La tercera y más intrincada escena corresponde a la experiencia introspectiva que vive Lina durante su injusto encerramiento en un lugar que se divulga al final de la novela: un sanatorio u hospital siquiátrico (1964: Il 1024) ${ }^{6}$. Allí escribe su autobiografía para ser leída sólo por ella, en un intento de afirmación de su individualidad y de su cordura. Este intento acusa una egocéntrica actitud esteticista más que irrefutablemente religiosa y mística como semeja a primera vista. Tras procurar lo bello en tiempos prosaicos se dedica a cultivar su misteriosa belleza interior. El culto del yo que profesa se manifiesta en un proceso de representación de su persona como obra de arte que posiciona su polifacética y talvez insana "conciencia individual" dentro de la conciencia de su época, un nexo sobre el cual doña Emilia discurre a finales del ochocientos (1976: 131-132). Además, debido a que se le niega punitivamente casi todo contacto humano poco después de descubrir el amor por sus congéneres Lina se transforma en una anónima mártir por la causa de la humanidad.

A continuación, se analiza la manera en que Pardo Bazán interpreta el contexto político-intelectual de la época bajo la lupa -la España de la Restauración entre 1898 y 1914, principalmente-, la estrategia narrativa que utiliza y las ideas que baraja, para luego examinar cada una de las escenas. Estos tres lustros fueron turbulentos para España, pero no lo fueron menos para el resto del Viejo Continente a juzgar por la apocalíptica brutalidad de la Primera Guerra Mundial que acaso ya se veía venir. En 1910 Pardo se refiere con tono profético a "todos los cataclismos que se presienten" en la civilización occidental (2006: 113). Décadas antes uno de sus personajes literarios teme que el progreso en Europa derive en "una conflagración universal" ${ }^{7}$. Estas meditaciones no evidencian que la condesa fuera clarividente sino más bien realzan su sagacidad en cuanto observadora crítica de su tiempo y entendedora de la relación dialéctica entre España y Europa. La conflagración universal puso fin a la Era del Imperio, no a la civilización occidental, aunque así lo interpretaron muchos $^{8}$. En cierto modo, Dulce dueño capta la tensa calma antes de la tormenta. Es un retrato epocal que no ofrece respuestas fáciles o inobjetablemente reivindicatorias ni para las naciones ni para sus ciudadanos. En medio de la acción se encuentra Lina, una mujer tan problemática como la época que le toca vivir.

\section{EN TORNO A LA "ÉPOCA MISERABLE"Y CÓMO LEERLA}

It is memory's truth, he insists, and only a madman would prefer someone else's version to his own (Salman Rushdie, Imaginary Homelands 25).

Lina Mascareñas se expresa de esta manera en uno de los períodos más atribulados de su vida:

\footnotetext{
${ }^{6}$ Lou Charnon-Deutsch ve el encierro como punitivo (Charnon, 1994: 185); contrariamente, Maryellen Bieder lo considera liberador (Bieder, 2002: 16, 17).

7 Así reflexiona Gabriel, decepcionado tras un viaje por las principales potencias occidentales, en La madre naturaleza (1887) (1964: I 316).
} 
¡Época miserable la nuestra, en que el bello granate de la sangre eficaz no se cuaja ya, no brilla! De las dos sangres excelentes, la del martirio y la de la guerra, la primera ya es algo como las piedras fabulosas y mágicas, que se han perdido; y la otra, también la quieren convertir en rubí raro, histórico, guardado tras la vitrina de un museo! (1964: II 1021).

En este diagnóstico de la modernidad el discurso religioso con énfasis en el martirio se entrecruza con el estético y el bélico-caballeresco e incluso el épico, amén de compendiar muchos de los recursos discursivos con que cuenta Lina. No se trata de una diagnosis moralizadora o misoneísta, sino de una apreciación fundamentalmente estética con ramificaciones políticas, históricas y literarias que Emilia Pardo Bazán plasma en Dulce dueño y en otros escritos contemporáneos.

Se arguye aquí que al examinar su época en esta novela Pardo Bazán controvierte las pretensiones de centralidad geográfica y de supremacía histórica de que se valen los principales imperios occidentales modernos para justificar su dominio global y, en cierta forma, la marginación de España y la subestimación de los españoles. G. W. F. Hegel (1770-1831) expone estas pretensiones antes de la Era del Imperio'. En lo concerniente al tiempo el pensador alemán asevera teleológicamente que Europa constituye el fin absoluto de la historia del mundo (Hegel, 1975: 197). De ello se deduce que lo que Hegel denomina el corazón de Europa, conformado por países como Francia y Alemania y la zona alpina, es el centro del mundo en términos espaciales (Hegel, 1975: 195). Influida por el malestar nacional pos-98, en La España de ayer y la de hoy Pardo lamenta el estado de su patria en su condición posimperial. No obstante, proclama a la vez el derecho de España "a figurar entre los pueblos cultos" en un intento de escrutarla endógenamente para contrarrestar el negroleyendismo que nace siglos antes allende sus fronteras (1901: 64). La condesa enuncia esta proclamación como española, pero también como europea sin pedir permiso y sin complejo de inferioridad ${ }^{10}$. Sabe bien que en juego está la posición de su país en el concierto de las naciones, así como la historia patria de la cual, según diría el personaje del epígrafe, sólo un loco preferiría una versión ajena a la propia.

La Primera Guerra Mundial confirma muchas de las apreciaciones impugnadoras acerca de Occidente que Pardo realiza desde el siglo XIX ${ }^{11}$. En Hernán Cortés y sus hazañas (1914), breve biografía publicada al inicio de la conflagración mundial, narra la conquista de Méjico a la luz del choque entre imperios occidentales a fin de resaltar la brutalidad inherente a las empresas imperialistas independientemente del período histórico, lo que provoca el cuestionamiento de conceptos como "progreso" y "humanidad" (1914: 15). El antisemitismo también pone en evidencia la atávica ferocidad de Occidente y la hipocresía de las acusaciones negroleyendistas. Agustín Almonte, el tercer y último pretendiente de Lina, comenta irónicamente que en Suiza ya no se queman judíos porque prima "la libertad

\footnotetext{
10 Noël Valis mantiene que muchos españoles durante el siglo XIX y a principios del siglo XX exhiben un sentido de inferioridad ante potencias como Francia e Inglaterra (2002: 32).

11 Ruiz-Ocaña Dueñas se refiere principalmente a los comentarios de la condesa en los años previos a la Gran Guerra (2015: 29-33). Para un análisis de la posición de esta respecto a la polémica aliadófilos-germanófilos durante la guerra, léase a Isabel Burdiel (2015: 11-27).
} 
de conciencia" (1964: Il 1006). Pardo puntualiza en un artículo de 1913 que debido a la expulsión sefardita en España no se dan "esos disturbios antisemíticos que renuevan hoy, en las naciones más cultas, los terrores de la Edad Media", pero si se dieran, se hablaría de "la renovada Inquisición" (2006: 315).

A la oscura violencia bélica y antisemita en Occidente Pardo Bazán contrapone un ideal cosmopolita presentado en Los poetas épicos cristianos (1895), su obra finisecular Ilena de ideas que trasvasa al siglo siguiente: "La edad de oro venidera -el ideal a que aspiramos-, será aquélla en que a muchos les duelan los dolores de su prójimo [. . .], en que el individuo se sienta más comunicado con la especie" (1895: 20). Para cuando publica Dulce dueño, su escepticismo se patentiza en que un personaje tan problemático como Lina sirve de conducto para la concreción de este ideal de altruismo y hermandad universal. Su reprobación de los pacifistas al inicio de la Gran Guerra parece clausurar definitivamente esta posibilidad (2006: 351).

Especificidad y no anomalía es lo que en última instancia Pardo Bazán reclama para su país, reduciendo la polarización entre este y el resto de Europa. En este sentido habría que matizarse el carácter de afirmación españolista y sensata crítica nacional de su labor literario-intelectual en los primeros lustros del siglo XX. María Elvira Roca Barea destaca el aporte en términos afines a los pardobazanianos de Vicente Blasco Ibáñez (18671928) y de Julián Juderías (1877-1918), autor de La leyenda negra y la verdad histórica (1914), a esta discusión de interés nacional (2016: 26-27) ${ }^{12}$. Paralelamente, en los años posteriores a la debacle colonial intelectuales españoles, muchos de ellos asociados con el regeneracionismo y la generación del 98, insisten en recalcar la presunta incompatibilidad entre España y Occidente, a menudo con una vehemencia casi histriónica que acusa signos de negroleyendismo interiorizado ${ }^{13}$. En la edición de 1917 de Psicología del pueblo español Rafael Altamira (1866-1951) censura que más de un español todavía se expresa con ecos de la "hispanofobia" pos-98 (Altamira, 1917: 20). Siete años antes, Pardo Bazán retrata a Agustín como un ambicioso político europeísta que evita las apreciaciones negativas de su país. "Conviene que salgamos de casa para aprender lo que debemos imitar y lo que debemos recordar, a fin de no ser demasiado pesimistas", le dice a Lina, demostrando valorar sin patrioterismo lo que su nación ofrece ${ }^{14}$. Por añadidura, al igual que su autora, ambos personajes se conducen por Europa como un europeo más, sin pedir permiso para serlo y sin complejos de inferioridad (1964: II 1004).

En cuanto a la narrativa, Pardo Bazán despliega su particular visión de España y de Occidente en el mundo moderno mediante la inclusión de abundantes fuentes, lo cual, a su vez, diafaniza su eclecticismo estilístico e ideológico ${ }^{15}$. Textos e imágenes de diversas épocas y procedencias confluyen en Dulce dueño de tal forma que se alteran la narración diacrónica y la noción de centralidad. Lina, la heredera de la fortuna de la familia Mascareñas, lidia en su autobiografía con esta incómoda confluencia espaciotemporal. La hagiografía de Santa Catalina de Alejandría (siglo IV) que se halla al principio de la novela, y cuyo autor es Carranza (uno de los mentores de la autobiógrafa), constituye un claro

15 La misma doña Emilia caracteriza su obra como ecléctica (1964: III 1081). Eduardo Ruiz-Ocaña Dueñas (2004: 149) e Íñigo Sánchez-Llama (2010: 27-29) se ocupan del tema. 
elemento convergente y una característica frecuentemente comentada por la crítica (1964: II 931). Pero es una antigua medalla con la efigie de la princesa incoerciblemente esteta y mártir virginal de la iglesia primigenia vestida a la usanza del siglo XV que dilucida la estructura palimpséstica de este pasaje. Al rato de decir que la alejandrina es una mujer "de su tiempo, y en otro siglo no se concibe", Carranza inspecciona la medalla y se contradice ligeramente al afirmar que "en cada época, la vestidura es al estilo de entonces" (1964: II 932, 933). El pasado, pues, no se borra ni se conserva inmutable y distante, sino que confluye y se reconstituye en cada época subsiguiente, por lo general inarmónicamente. De ahí que Lina, cuyo verdadero nombre es Catalina como la fallecida matriarca de la familia Mascareñas, se erija en una reconstitución de su santa patrona en la época miserable. También a través de Santa Catalina se intersecan España, Alejandría, Grecia y el mundo cristiano en general, donde se la adora por siglos.

La mayor queja que expresa Lina acerca del mundo moderno es la predominancia de lo tedioso, lo prosaico y lo antiestético, y contra estos elementos combate enconadamente para proteger su yo. Este tema del individuo en y ante su entorno puede considerarse a partir del concepto del culto del yo teorizado por Maurice Barrès (1862-1923) que Pardo analiza en su artículo de 1892 sobre algunas obras de su homólogo francés (muy poco estudiado con respecto a ella) (1964: III 1069-1072) ${ }^{16}$. Doña Emilia alude a dicho concepto en Dulce dueño, lo que ocasiona que en la novela converjan el decadentismo y otros movimientos artístico-literarios e intelectuales de finales del siglo XIX con que se asocia a Barrès $^{17}$. El hecho de que la palabra culto significa veneración y cultivo, conexiones semánticas a las que se refiere Lina cuando escribe sobre el "culto que profeso a mi persona" y a "mi autocultivo estético" respectivamente, constituye un ejemplo de esta alusión (1964: II 960,981). Sin embargo, se dificulta hablar de influjo directo puesto que Pardo idea paródicamente un personaje femenino con el fin de colacionar nociones pensadas para individuos masculinos ${ }^{18}$.

Uno de los aspectos más salientes del artículo de la condesa es su comentario favorable del "método práctico-ideal, el culto del yo" barresiano (1964: III 1071). Para explicar el concepto y el método, Pardo inserta una cita larga que se incluye parcialmente a continuación:

Los jóvenes sinceros que no encuentran, al entrar en la vida, un dueño a quien servir, sea axioma, religión o príncipe entre los hombres -algo que se les imponga-, tienen

\footnotetext{
16 Nelly Clèmessy comenta el "culto al Yo" de Barrés sin vincularlo con Dulce dueño (Clèmessy, 1981: I 393, 394).

17 Maryellen Bieder analiza el influjo del decadentismo en Dulce dueño (2002: 7-21). Para un comentario sobre la relación entre Barrès y el decadentismo, léase a Anthony A. Greaves (1978: 13).

18 Pardo alude con mucho humor al culto del yo barresiano en Memorias de un solterón (1894). El ridículo autobiógrafo llamado Mauro Pareja, una variante homófona del nombre del autor francés, se refiere al "culto de mi propia persona" para relatar su metódica vida estructurada en torno a su egocéntrica decisión de no casarse y para describir su exquisitez que lo acerca al dandi (1964: II 449, 457). En su caracterización del dandi Charles Baudelaire (1821-1867) resalta justamente el culto del yo (1968: 560). Por otra parte, la figura del dandi en la Europa finisecular la encarna un hombre afeminado con inclinaciones artísticas, según Rita Felski (1996: 96); con Lina, la autora gallega completa lúdicamente su afeminación.
} 
ante todo que servir a su yo. Lo primero es afirmarse existentes. Cuando sean fuertes y dueños de su alma, que se conviertan a la Humanidad, y busquen senda común donde armonizarse.

Nuestro yo no es inmutable: hay que defenderlo y crearlo todos los días (1964: III 1071).

Tal vez el aspecto más relevante en este texto sea el uso de la palabra dueño en sus numerosas acepciones, rasgo que complica la lectura del dulce dueño como figura irrefutablemente personalizada, sobre todo masculina (humana o divinamente ajena), que Lina procura en diferentes etapas de su relato. El análisis de las tres escenas mencionadas en la introducción a desarrollarse en las siguientes secciones trasparenta varios "dueños". Estos son, pues llegan a imponérsele o a apoderarse de ella en distintas coyunturas existenciales, la belleza (concepto polisémico que llega a abarcar incluso lo grotesco), el amor hacia la humanidad y por último su yo, vale decir, su misteriosa - y posiblemente enferma- interioridad, esa moderna "conciencia, desgajada" que Pardo indaga en su estudio de 1911 sobre Lev Tolstói (1828-1910) (1964: III 1510).

Dado que hacia el final de su relato Lina parece adscribirse al misticismo con la finalidad de trascender espiritual y sobrenaturalmente su inmediatez física, es inevitable referirse al elemento religioso como parte de la confluencia espaciotemporal en la novela. Ahora bien, Susan Kirkpatrick afirma sobre Dulce dueño que "the text does not allow the religious interpretation to preside securely over other possibilities" (Kirkpatrick, 1999: 135). Ciertamente doña Emilia es consciente del carácter polisémico del vocablo misticismo pues acepta que además de su consabido significado teológico abarca circunstancias de índole no inobjetablemente religiosa (1964: III 807-808). Si se toma en cuenta la aseveración de Marcelino Menéndez y Pelayo (1856-1912) de que lo que caracteriza a la estética mística es la presencia divina, se antoja innegable que las vivencias extáticas de Lina son de origen antes sicológico que sobrenatural (Menéndez, 1920: III 163-164). Y a semejanza del autor de Historia de las ideas estéticas en España (1883-1889), Pardo opta por enfocarse en los aspectos estéticos antes que en los teológicos y filosóficos del discurso místico, agregando la dimensión sicológica a sus cavilaciones (Menéndez, 1920: III 122).0

El discurso místico, empero, no debería verse como una reliquia premoderna porque en realidad es reconstituido para discutir temas sicológicos en una época anterior a la concepción tripartita de la mente que propondrá Sigmund Freud (1856-1939) como la de entresiglos (Freud, 1965: 72). En Degeneración (1892), el húngaro Max Nordau (18491923) impugna desde una perspectiva pretendidamente científica la mentalidad moderna, patente en artistas y literatos, por considerarla sobremanera inestable a raíz de su presunta configuración mística (Nordau 1895: 15, 45, 300). Contrariamente, según Pardo, quien estudia las teorías de Nordau en La nueva cuestión palpitante (1894), el lenguaje científico y racionalista no es suficiente para desentrañar el "profundo misterio" en que se encuentra "la función íntima y sublime del cerebro humano" (1964: III 1180).

La imprevisible complejidad sicológica de Lina y la densidad fontal de su relato se evidencian asimismo en toda la gama de papeles que desempeña en varias esferas sociales, señaladamente, la pupila, la doncella andante, la esteta, la penitente, la asceta, la altruista, 
la mártir, además de la autobiógrafa. Viviendo modestamente en Alcalá de Henares y también tras heredar una fortuna que le permite viajar extensamente, desempeña estos papeles ante todo para contender contra hombres que quieren controlarla. Son desvaídas permutaciones de figuras de autoridad y del saber y de caballeros andantes mediante las cuales se socavan modelos de masculinidad y de feminidad transmitidos por productos culturales como la literatura.

Esta discusión está ligada al hecho de que Lina escribe su propia historia. En rigor, su relación con los hombres puede entenderse a partir de la conquista como tropo de una lucha existencial y estético-intelectual fundamentada en escribir y leer narraciones personales cual actos de conquistar o ser conquistado. José María Mascareñas, su primo granadino y segundo pretendiente, proporciona un ejemplo de ello: "Ahora quisiera leé en ti. Tú eres un libro de letra menúa (1964: II 984). Al no poder leerla, cae derrotado; y la vencedora escribe la versión oficial de la lid y de su "conquista" de Granada.

A fin de apreciar el tropo de la conquista ayuda escudriñar la figura de la doncella andante que corporeiza Lina. En el capítulo de Los poetas dedicado a Torcuato Tasso (15441595) Pardo Bazán la concibe como una mujer indómita que "asalta ciudades, rompe lanzas y riñe batallas, sin perder la delicadeza y gracias del sexo", lo que implica que no se trata simplemente de una virago o un caballero andante travestido (1895: 214). Es cierto que la autobiógrafa no se refiere explícitamente a esta estampa histórico-literaria en su escrito y que entre sus atributos no se cuentan ni la delicadeza ni la gracia. No obstante, el discurso bélico-caballeresco con tintes épicos que en parte estructura su autobiografía capta adecuadamente el modo autosuficiente en que se relaciona con la mayoría de sus circunstantes masculinos y femeninos.

En la mayoría de las batallas que Lina disputa como doncella andante, puja en tándem la esteta, lo cual posibilita la confluencia de la cultura finisecular (el dandi) y la clásica (Santa Catalina ${ }^{19}$. Si bien parece que lo que ella busca desde el principio de la novela es un dulce dueño, en este caso un hombre que la enamore, su móvil más acuciante es la búsqueda de la hermosura en un mundo antiestético habitado por seres que a ratos describe con toques terroríficos del Goya (1746-1828) de las Pinturas negras (1819-1823) antes que del Naturalismo (1964: II 973-974, 999, 1019) ${ }^{\mathbf{2 0}}$. Hay, por ende, una pugna dialéctica incesante entre lo bello (manifiesto especialmente en objetos, lugares, el cuerpo y el saber) y lo grotesco (lo prosaico, también lo sobrecogedor) en su relato autobiográfico. Lo que empuja a la autobiógrafa es una egocéntrica procura de distinción, o más bien de superioridad, para trascender su entorno social ${ }^{21}$.

Más cerca de la abnegación que del egocentrismo se encuentra el sentimiento patrio, de mucha importancia para Pardo Bazán, tal cual lo expresa en "Apuntes autobiográficos" (1886) (1964: III 701). En su discusión sobre la doncella andante la autora gallega destaca este sentimiento conglobando figuras femeninas que a lo largo de la historia "desdeñan

\footnotetext{
19 Nordau estudia movimientos finiseculares como el esteticismo y se refiere al dandi (1905: 317, 319).

20 En 1906, Pardo asevera que Goya es "el padre de la pintura moderna” y que su influencia se nota en los movimientos literarios finiseculares, insinuando que ella no rechaza este influjo (1964: III 1295, 1294).

21 Kathy Bacon comenta la busca de distinción que realiza Lina (2007: 152).
} 
el egoísta subjetivismo de la pasión y viven en la esfera objetiva del amor de patria y del entusiasmo de la gloria" (1895: 219). Esto corrobora la afirmación de Carmen PereiraMuro de que "el principal espacio masculino simbólico que Pardo reclama para la mujer es la nación" (Pereira-Muro, 2013: 147), aserto vinculado con sus comentarios sobre las preocupaciones nacionalistas y feministas de la condesa (Pereira-Muro, 2013: 180-181). Pese a que su móvil no es el patriotismo, Lina se moviliza en este espacio con desdeñosa soltura propia del conquistador occidental, tanto dentro como fuera de su país. De ahí que al llegar a Paris como representante de España no esconda su desdén esteticista por lo que mira: "Yo, española, no puedo sentir hondo aquí, ni aun por contraste con las calles infestadas de taxímetros y otras cosas feas [. . .] Patullo en la prosa parisiense" (1964: II 1001). La incursión en la capital francesa es solo el preámbulo de la que llevará cabo en el Lago Léman en Suiza, una nación que, irónicamente igual que la España pos-98, carece de imperio.

\section{EL IMPERIO Y LA CONQUISTA GLOBAL}

Un día a la más pequeña/ le vino la inclinación de vestirse de soldado/ y a la guerra se marchó ("Romance de la doncella guerrera", Romancero 267).

Larga es la ruta que recorre Lina Mascareñas de Alcalá de Henares al Lago Léman ubicado en el corazón de Europa occidental y, hegelianamente, del mundo. Cuando Carranza le avisa que le ha dicho a Agustín que ella vale "un imperio", inadvertida y simbólicamente la inviste con la misión personal y patriótica de conquistar (1964: II 996). Esta hiperbólica evaluación, ejemplo de la ironía de Pardo Bazán, convierte la reflexión de Lina al Ilegar a Suiza en un proyecto imperial: "Noto en Suiza lo contrario que en Granada. A Granada pude yo hacerla para mí" (1964: II 1001). El proyecto se torna ecuménico durante su estadía en la nación centroeuropea cuando Agustín le propone emular a famosas parejas de la historia como Marco Antonio y Cleopatra "para dominar el mundo" (1964: II 1003).

Debido a conflictos de afecto y de poder que Lina relata entrelazando discursos estetizantes y épico-caballerescos, a través de Agustín remanece asimismo la "amenaza española", la clase de discordia que ocurre cuando un compatriota resulta más peligroso que el enemigo afrontada por Hernán Cortés (1914: 87). El ahogamiento del pretendiente que más cerca está de apoderarse de ella y devenir su dueño ocasiona que la victoria sobre la tempestad lacustre y la consiguiente conquista global le pertenezcan a la doncella andante Ilamada Catalina Mascareñas emblematizando a su patria (pos)imperial. Se está ante una opaca reconstitución de una de las sangres excelentes que ella anhela.

Ya antes de esta victoria pírrica la aguerrida autobiógrafa rivaliza irónicamente con Inglaterra, el imperio global europeo más poderoso de la era. Mientras viaja por Suiza en tren poco antes de reencontrarse con Agustín, una Lina desencantada con el amor 
observa un matrimonio inglés compuesto por un hombre mayor y obeso y una jovencita sumisa. Imagina que le habla directamente a la esposa: “¡Qué fuerza tendrá el engaño para que tu cabecita de arcángel prerrafaelista, nimbada de oro fluido, se vuelva con tal insistencia hacia ese pedazo de rubicunda carne, amasada con lonchas de buey crudo [...]!" (1964: II 1002). Es esta una escena alegórica y satírica en que se pinta a Inglaterra como monstruosamente autocomplaciente y depredadora con implicaciones pedófilas. La mirada goyesca de la doncella conquistadora es apabullante.

Sin embargo, desde el momento en que Lina sale del corazón geográfico de la España peninsular que es Alcalá de Henares rumbo a Madrid para convertirse en la "heredera universal" de la fortuna de la tía comienza a conquistar obstáculos temporales y espaciales decidida a seguir solo su "ley propia" (1964: II 953, 956). Rápidamente se apodera de todo lo que perteneció a quien, según colige posteriormente, fue su madre y la condenó a un austero y desamorado exilio provincial. Para completar su victoria, la narradora confina a doña Catalina a un papel secundario dentro de su autobiografía (1964: II 965).

Luego de España, sigue Europa. Vacilante aunque sin bajar la guardia, Lina le cede el liderazgo de la relación a Agustín, so acuerdo caballeresco de que los unifique la procura del poder y no la pasión erótica (1964: II 1004). Pero el pretendiente al poco tiempo confiesa estar enamorado, convirtiéndose en una antiestética fuerza invasora que la impele a defender su yo "barresianamente" y a tacharlo de falso caballero (1964: II 1015). Cuando él acepta navegar por el Lago Léman en plena tempestad como desea ella en su morbosa busca de lo inusitado para combatir el tedio de la prosaica vida moderna, la exime de toda responsabilidad de las fatales consecuencias. Inmediatamente después del trágico y sobrecogedor incidente, el relato desemboca en una representación irónica e hiperbólicamente épica de cómo España anuncia su presencia en asuntos europeos y planetarios. Lina cuenta los terribles acontecimientos subrayando su alcance mundial gracias a los medios de comunicación modernos: “De la catástrofe había hablado la Prensa mundial en emocionantes telegramas de las agencias; éramos los "dos amantes españoles" víctimas de una romántica imprudencia en el lago. En España, mi ignorado nombre se popularizó" (II 1012-1013).

Con la insólita postal alpina y sus repercusiones individuales, nacionales y globales, Pardo Bazán posibilita la confluencia palimpséstica de tiempos y espacios. Espacialmente, ello se evidencia en el poroso umbral entre el centro y la periferia que revela la fluidez y la interpenetración en lugar de la separación tajante e irreversible. Temporalmente, se aprecia en la rápida diseminación de noticias mediante la cual los eventos se dan a conocer mundialmente antes de que los involucrados den razón de los mismos, cual si el futuro antecediera al presente para luego coexistir incómodamente. Esto, sumado a varias alusiones a figuras literarias (Lamartine, Oscar Wilde) e históricas (Hernán Cortés, Cánovas) y a la huella de violencia antisemita en Suiza, propicia que un lago en el corazón de Europa sea el sitio de enlazamiento de incontables épocas, espacios, discursos e imágenes, un collage narrativo que refleja la maestría ecléctica de la condesa. 


\section{LA HUMANIDAD Y EL ABRAZO COSMOPOLITA}

La piedad al fin; la piedad humana, el reconocimiento de que alguien existe para mí, de que el dolor ajeno es el dolor mío. Un impulso irresistible, ardiente, sin freno, de ternura infinita, de amor, de amor sin límites (1964: II 1023).

Tras la muerte de Agustín, un suceso personal que recibe atención planetaria, o al menos así lo reporta Lina, ella descubre la compasión por sus congéneres cuando cuida de una chiquilla repugnante y peligrosamente enferma llamada Torcuata (¿una traviesa alusión a Tasso?). Como resultado, se convierte en una anónima iniciada, y luego en una mártir por la causa de la humanidad. Su transformación la acerca al hiperbólico ideal cosmopolita de abrazar a "la especie" que Pardo formula tres lustros antes no en términos biológicos sino afectivos y cosmopolitas (1895: 20). Por un momento breve y acaso redentor al besar a Torcuata en la sublime y grotesca escena que acaece en un remoto valle en España el amor que Lina siente por la humanidad efímeramente se apodera de ella y deviene su dueño. Previo a esta circunstancia extrema libra numerosas batallas.

Más por razones egoístas y estéticas que por remordimiento a causa de la tragedia en el corazón de Europa occidental, Lina empieza un período de penitencia que la conducirá a un estado de ascetismo durante su forzado encerramiento (1964: II 1016-1026). Muestras de la tendencia ascética en ella, empero, se observan con anterioridad. Por ejemplo, tras su viaje a Andalucía admite que a punto estuvo de rendirse a la sensualidad de su primo José María, aprieto del que se salva por una indiscreción de este (una noche lo sorprende saliendo de la habitación de la sirvienta que viaja con ella) (1964: Il 988-989). Así se expresa la autocronista: “¿Cómo me dejé arrastrar por el instinto? Al rendirme - porque moralmente rendida estuve- [...] He descubierto en mí una bestezuela brava... a la cual me creía superior" (1964: II 990). Vencido el falso caballero andante, ella decide vencer a su cuerpo, pero primero debe aprender más sobre el sexo, un tema que desconoce tanto en la teoría como en la práctica.

Al azar Lina conoce al doctor Barnuevo, quien tras su sobresalto inicial accede a darle la lección científica que quiere. "Voy apoderándome de él", escribe, con la seguridad de una avezada conquistadora (1964: II 992). Cuando la improvisada estudiante destaca la vergüenza que hay en torno a la función sexual, el no menos improvisado mentor responde tópicamente: "Por necesaria, la Naturaleza la ha revestido de atractivo, la ha rodeado de nieblas encantadoras. La especie exige..." (1964: II 992). Cortante y enérgica es la respuesta de Lina, hablando acerca de la especie en su acepción estrictamente biológica: "Yo no quiero nada con la especie... Soy el individuo." (1964: II 992). De esta manera comprueba que tras los eufemismos poéticos, científicos y religiosos que elabora la civilización en torno al amor subsiste lo que ella percibe como la antiestética crudeza del cuerpo humano en su función sexual. Su esteticismo la blinda y la lleva a expresar que siente "repulsión 
y tedio infinito" no solo hacia los hombres, sino hacia todos sus congéneres, a quienes observa con distanciamiento goyesco (1964: II 974)22.

La penitencia más significativa que Lina se impone consiste en servir a Torcuata y a su abuela, unas paupérrimas colmeneras que radican en un pequeño oasis en pleno páramo castellano adonde llega en un vagón de tercera. Mientras desempeña servicios domésticos por estos seres que ofenden su "instinto estético" mantiene el deseo de gozar de una hermosa vivencia extática que trascienda lo prosaico, quizá de forma inefablemente sobrenatural como Santa Catalina (1964: II 1021, 940). Cuando Torcuata se enferma, este egocéntrico deseo místico se interrumpe. El instante supremo de piedad humana o de abnegación por sus semejantes ocurre cuando Lina besa un rostro deturpado (1964: II $1023)^{23}$. Si bien esta escena semeja contradecir el culto a la hermosura como signo de superioridad que la autobiógrafa encarna y preconiza, en puridad revela un cambio en su cosmovisión estética y afectiva. En vez de observar el mundo desde una perspectiva distanciante al igual que Goya, acepta formar parte de una pintura negra del maestro aragonés, lo cual implica que en ese momento se siente parte del género humano, solidarizándose con sus miembros más necesitados.

Sea como fuere, el contacto altruista con la humanidad que Lina protagoniza no la redime pues, a desemejanza del incidente en el Lago Léman, pasa prácticamente desapercibido, evidencia del escepticismo de Pardo con respecto a su propio ideal de la edad de oro cosmopolita. Tampoco redime a Occidente, probablemente una sutil contravención pardobazaniana al Ilamamiento a que España imponga su espiritualidad en Europa efectuado por Unamuno en 1906 (Unamuno 1964: III 1124). Estas limitaciones no impiden que el interactuar con mujeres, algo infrecuente en su vida, posibilite la formación de una comunidad. Es un insólito y humilde trasunto de órdenes como la que funda Santa Teresa, a quien Lina admira en gran medida por su heroica ansia de martirio (1964: II 1021) ${ }^{24}$. Independientemente de su brevedad, esta experiencia solidaria resulta más productiva que toda una vida de lidiar con varones. Y son varones, principalmente el padre de José María a fin de apoderarse de la herencia, quienes la internan aduciendo su comportamiento errático tras la muerte de Almonte.

La decisión de negarle casi todo trato con sus congéneres ni bien aprende a amarlos de hecho convierte a Lina en una mártir por la causa de la humanidad. Irónicamente, su martirio constituye un castigo médico y burocrático, decepcionante reconstitución palimpséstica de la otra sangre excelente en la época miserable que es la modernidad. Pero

\footnotetext{
22 La asexualidad y la aparente incapacidad de amar de Lina podrían explicarse a partir de las reflexiones de Tolstói en torno a la reproducción humana. Una de las teorías más polémicas del aristócrata ruso que la condesa examina con reservas es la anárquica condenación de la fertilidad que supondría "la extinción de la raza mediante la continencia" (1964: III 1518).

23 El beso de Lina a la chiquilla se asemeja al de San Francisco de Asís (1182-1226) a un leproso, incidente que Pardo comenta en su monumental biografía del religioso italiano a quien presenta como un esteta que lucha por sobreponerse a lo grotesco del mundo (1886: 18, 19). DuPont examina las conexiones entre San Francisco y Lina resaltando la manera en que se entrelazan la espiritualidad y la estética (DuPont, 2012: 115-118).

24 Consúltese a DuPont para un análisis de la impronta de Santa Teresa y su legado místico en la obra pardobazaniana (DuPont, 2012: 91-128).
} 
a pesar de que no logra trascender espiritual y sobrenaturalmente su cuerpo según desea, encuentra un tipo de trascendencia altruista, o sea, social y terrena. Su cuerpo, protección contra los antiestéticos conatos de conquista de mentores y pretendientes, en lugar de debilitarse al exponerse física y afectivamente para cuidar a otra persona se fortalece. Ahora Lina Mascareñas está lista para una travesía introspectiva.

\section{EL CULTO DEL YO Y EL YO COMO OBRA DE ARTE}

Los jóvenes sinceros que no encuentran, al entrar en la vida, un dueño a quien servir [. . .] tienen ante todo que servir a su yo (1964: III 1071).

Estando casi totalmente aislada de la sociedad dentro de una celda en un sanatorio tras haber conquistado el planeta y aceptado afectivamente a la humanidad, Lina emprende la exploración y la conquista de su yo interior. Su desgajada o fragmentaria conciencia moderna se le manifiesta de manera bellamente misteriosa impidiéndole articular y comprender todo lo que siente y piensa. Este misterio que se origina "allá en lo arcano" de su ser se apodera de ella, deviniendo un dueño gratificador antes que frustrante (1964: II 1024). No obstante, aun cuando no lo explicita, su fuero interno bien podría estar enfermo. Y si este se erige en un barómetro de la modernidad occidental -así parece entenderlo Pardo Bazán-, entonces la conciencia de Occidente, racionalista y utilitaria, está en crisis $^{25}$. Correspondientemente, el culto a su yo constituye un intento de encontrar belleza y placer en un mundo prosaico, mientras que la construcción de su persona como obra de arte es la forma egocéntrica que adquiere dicho intento ${ }^{26}$. Ya que utiliza el lenguaje místico para hablar de estas incidencias, se requiere una explicación teniendo en cuenta la confluencia ecléctica que Pardo imprime en su escritura mediante la cual el elemento religioso se entrelaza con el sicológico o afectivo y el estético.

Dicho entrelazamiento se intrinca pues inmediatamente después de expresar con una retórica cosmopolita el desbordante amor por la humanidad que se apodera de ella como un dueño, Lina recurre al discurso místico para referirse a su subsecuente estado extático: “mi corazón se disuelve, se liquida [...] ¡El Dueño, al fin, que Ilega, que me rodea [...]! (1964: Il 1023). Con todo, esta especie de arrebato religioso también puede leerse como una experiencia estética que surge en la arcanidad síquica de Lina cuando menos por dos razones $^{27}$. Primero, a diferencia de Carranza en su hagiografía de Santa Catalina, la autobiógrafa no hace mención explícita de Jesucristo, de ahí que el pronombre "Él"

\footnotetext{
25 Carmen Pereira-Muro se aproxima al tema en términos del "dejarse ir" femenino como alternativa a la "voluntad" masculina (2013: 175). En 1892 Pardo escribe una apología de la locura nacional como "fuente de inspiración estética, bendita y salvadora" y tilda de "eternamente prosaicas" a "las naciones que han perdido la facultad de enloquecer", reconvención dirigida a Francia por su excesivo racionalismo (1964: III 1076).

26 Rita Felski estudia el concepto del yo como obra de arte que relaciona con la figura del dandi (1995: 96-97).

27 Cristina Mazzoni discute la conexión entre el misticismo y la histeria en diferentes campos del saber decimonónico (1996: 1-7, 19-20, 42).
} 
se constituya en un tropo abierto a interpretaciones no religiosas, o en todo caso no forzosamente cristológicas. Segundo, recurre al lenguaje místico debido a las sobredichas limitaciones discursivas para verbalizar la exploración de la mente humana en la época. El dulce dueño que invoca en la última frase de su relato, en consecuencia, no es por fuerza una presencia formada exterior y sobrenaturalmente, sino ella misma. Ese tan esperado "Él" es su propio yo, o su conciencia desgajada, que se apodera de ella (1964: II 1026). Se trata de una faceta impredecible de su yo producto de la disociación que se advierte en "A la conciencia", un poema de Benito Feijóo (1676-1764) citado por la autora gallega: "Noche y día, sin parar,/ tu agitación misteriosa/ un momento no reposa/ ni me deja reposar" (1964: III 755).

Lina describe su experiencia extática tras besar a Torcuata por medio del tropo de la disolución del yo. Es la misma sensación que se apodera de ella esporádicamente mientras permanece expectante en su celda (1964: II 1024). Siente algo similar como mínimo en otras dos ocasiones que no asocia automáticamente con lo místico. Una le sucede durante una presentación de la ópera Lohengrin (1850) de Richard Wagner (1813-1883) al dejarse Ilevar por la belleza de la música y por la temática épico-caballeresca (1964: II 971). La otra acontece en La Alhambra cuando, todavía guiada por la ilusión fundamentada en el leitmotiv erótico de que un hombre llegue a ser su dulce dueño, la impacta la hermosura del lugar (1964: II 983).

Lo que tienen en común estas situaciones es la impronta del esteticismo en el comportamiento y el pensamiento de Lina. Sin duda la belleza -o el buscar, alcanzar y disfrutar lo bello- en sus múltiples variantes prepondera a lo largo de su autobiografía. De hecho, los discursos que emplea y las imágenes que incorpora para hilvanar su relato la atraen por conllevar o evocar hermosura. Acaso el aspecto más fascinante de las sensaciones extáticas que la cautivan en el tramo final de su narración es que le parecen hermosas tanto por el misterio que las caracteriza como por el espacio en que se producen, vale decir, su yo interno.

El deseo de embellecimiento de este espacio interior comienza decididamente mientras Lina cumple su antiestética y tediosa penitencia autoimpuesta:

Y es en mi interior donde aspiro a la vida radiante, beatífica, divina del amor. Es en mi interior donde quiero divinizarme, ser lo celeste de la hermosura. ¿Cómo buscar el interior encielamiento? No con actos externos, no con mi cuerpo pisoteado, y mi rostro afeado y mi ropa vulgar. Si dentro está el cielo del amor, dentro debe de estar el modo de conquistarlo (1964: II 1019).

Su mística ansia por alcanzar el amor divino, consignada curiosamente en términos de conquista, la empuja no sólo a imponerse penitencias sino también a prepararse interiormente para cuando sobrevenga el contacto. Estas previsiones introspectivas, junto al cuidado que le brinda a su cuerpo en otras etapas de su vida, conforman su "autocultivo estético", ese acto o ritual de servir a su persona (1964: II 981). Posteriormente, ya como practicante del culto de su yo en la ascética austeridad de su celda (muestra de que la belleza exterior ha sido relegada), goza recordando las recientes visitas del dueño, sumida en "la ansiosa espera" del siguiente arrebato extático (1964: II 1024). La incertidumbre no la exaspera; al contrario, declara sentirse feliz, un estado que confirma, entre otras cosas, que su yo no es inmutable por lo cual debe 
reconfeccionarlo incesantemente (según recomienda Barrés).

Podría decirse, por lo tanto, que con un palimpsesto de elementos estéticos y sicológicos de trasfondo, Lina contempla su yo interior cual si fuera una obra de arte en constante transformación. Al poco tiempo de recibir la herencia de los Mascareñas, planea usar su fortuna para "artistizar" su nueva vida, una voz ideoléctica que, vista retrospectivamente, le señala una misión personal manifiesta fundamentalmente en su búsqueda estetizante de superioridad (1964: II 962-963). Pero si bien durante largos pasajes de su narración procura embellecer su exterioridad y lucir en público su cuerpo (por lo general, elegantemente ataviada y en espacios estéticamente placenteros) y su intelecto (con su lucha por escribir y leer mejor que sus adversarios), en los episodios postreros el placer contemplativo es un acto privado. Y artístico. Con motivo del estreno madrileño de la versión operática de Salomé en 1910, Pardo Bazán comenta la actividad del artista moderno: el "filisteísmo" imperante lo estimula "a recogerse en sí mismo, aislándose en su fruición estética e intelectual" (1994: 49). Recogida en sí misma, Lina se recrea con su obra maestra: ella.

Cabe reiterar que la peculiar narradora se sirve del lenguaje místico para trazar este encuentro consigo misma como una presencia hermosa mas ajena en su ser, manteniéndose disociada, cerca y lejos de sí misma, ejemplo de la conciencia desgajada que doña Emilia discierne en el mundo moderno. Tal condición exhibe asimismo la confluencia en la época miserable del discurso místico en su secularizada reconstitución "científica" para explorar la mente humana y su patológica inestabilidad. Las "sombras y caricaturas goyescas" que mortifican a Lina son reemplazadas por un arcádico escenario mental -menciona un bosque- en el que su dueño se le aparece de forma caprichosamente esporádica (1964: II 999, 1024).

Se trata de una repetición indefinida, esto es, una experiencia disteleológica e irracionalista (afectiva, subconsciente) que confina a Lina en su fuero interno, más allá de las convenciones de tiempo y espacio. A nivel personal, se halla en y ante sí misma, disfrutando los preciosos encuentros que mitigan fugazmente su fragmentación síquica. Igualmente, en la hiperbólica intersección narrativa con el nivel nacional y el supranacional ella pone en evidencia las pretensiones de centralidad geográfica y de supremacía histórica teleológicamente delineada de la modernidad en Occidente, la civilización que no quiere o no puede percatarse de su inherente oscuridad quizás por mor de su propia conciencia desgajada.

Es en el último capítulo de su autobiografía que Lina escribe unos renglones que complican la lectura de toda la novela, particularmente en lo atañedero a su conciencia y su salud mental: "En este asilo, donde me recluyeron, escribo estos apuntes que nadie verá, y solo yo repaso por gusto de convencerme de que estoy cuerda, sana de alma y cuerpo" (1964: II 1024). La posibilidad de que esté loca obliga a reevaluar toda su narración, desde sus decisiones personales hasta las discursivas. A la vez, esta cita convierte al lector en un adversario de la protagonista de Dulce dueño porque recelar de su afirmación de cordura supone creer poder leerla mejor de lo que ella se lee, como sus mentores y pretendientes en su momento. Tampoco resulta fácil aceptar su aseveración de que se encuentra feliz 
cuando parece que se está ante los desvaríos de una mujer ilusa e histérica que ha sido marginada en un sanatorio mental por una sociedad retrógrada y opresiva. Pardo Bazán no ofrece respuestas satisfactorias, mucho menos lecciones edificantes; su multifacético personaje no es una figura ejemplar.

Además, el hecho de que Lina no espera ser leída por otros suscita que todo acto de lectura de su autobiografía acarree una agresión contra una mujer celosamente privada. Lo mismo puede decirse de escribir sobre dicho texto pues esto implica poder reescribirlo con mayor corrección que ella. Es un fascinante juego instituido por la condesa que el crítico literario no consigue evitar. La situación se agrava por tratarse de una etapa decisiva en la historia de una mujer que afirma no seguir más ley que la suya, y solo una persona demente preferiría una versión ajena a la propia. Pardo Bazán opina algo parecido sobre la versión negroleyendista que autores foráneos, y varios compatriotas, escriben acerca de la historia de España relegándola temporal y espacialmente. A través de Lina Mascareñas y sus experiencias imperiales, cosmopolitas y egocéntricas invierte el proceso, revelando irónicamente el lado oscuro -la leyenda negra- de la civilización de Occidente de la que España también forma parte. Lo hace sin pedir permiso y sin complejo de inferioridad.

\section{BIBLIOGRAFÍA}

Alcalá Galiano, Álvaro (1915): La verdad sobre la guerra. Orígenes y aspectos del conflicto europeo, Madrid, Imprenta de Fortanet.

Altamira, Rafael (1917): Psicología del pueblo español, Barcelona, Editorial Minerva.

Bacon, Kathy (2007): Negotiating Sainthood. Distinction, Cursilería and Saintliness in Spanish Novels, London, Legenda.

Baudelaire, Charles (1968): CEuvres completes, Paris, Éditions du Seuil.

Bieder, Maryellen (2002): “Divina y perversa: la mujer decadente en Dulce dueño de Emilia Pardo Bazán", Perversas y divinas. La representación de la mujer en las literaturas hispánicas: El fin de siglo y/o el fin de milenio actual. Ed. Carme Riera, Meri Torras e Isabel Clúa, Valencia, Ediciones eXcultura, pp. 7-21.

Blanco, Alda (2012): Cultura y conciencia imperial en la España del siglo XIX, València, Publicaciones de la Universitat de València.

Blasco Ibáñez, Vicente (1966): Discursos literarios, Valencia, Prometeo, 1966.

Borges, Jorge Luis (1980): El Aleph, Madrid, Alianza.

Britt Arredondo, Christopher (2005): Quixotism. The Imaginative Denial of Spain's Loss of Empire, New York, State University of New York Press.

Burdiel, Isabel (2015): "La última encrucijada: Emilia Pardo Bazán ante la Gran Guerra", La Tribuna. Cadernos de Estudios da Casa Museo Emilia Pardo Bazán, 10, pp. 11-27. 
Cerezo Galán, Pedro (2003): El mal del siglo. El conflicto entre Ilustración y Romanticismo en la crisis finisecular del siglo XIX, Madrid, Biblioteca Nueva.

Charnon-Deutsch, Lou (1994): Narratives of Desire. Nineteenth-Century Spanish Fiction by Women, University Park, Pennsylvania State University Press.

Clèmessy, Nelly (1981): Emilia Pardo Bazán como novelista: De la teoría a la práctica, Vol. 1, Madrid, Fundación Universitaria Española.

Costa, Joaquín (1998): Oligarquía y caciquismo como forma actual de gobierno de España, urgencia y modo de cambiarla, Madrid, Biblioteca Nueva.

DuPont, Denise (2012): Writing Teresa. The Saint from Ávila at the fin-de-siglo, Lewisburg, Bucknell University Press.

Felski, Rita (1995): The Gender of Modernity, Cambridge, Harvard University Press.

Freud, Sigmund (1965): New Introductory Lectures on Psychoanalysis, New York, Norton.

Greaves, Anthony A. (1978): Maurice Barrès, Boston, Twayne Publishers.

Gutiérrez Álvarez, Ruth María (2017): "La batalla ideológica entre la carne y el espíritu. Una aproximación a los personajes femeninos de las últimas novelas de Emilia Pardo Bazán", La Tribuna. Cadernos de Estudios da Casa Museo Emilia Pardo Bazán, 12, pp. 23-36.

Hegel, G. W. F. (1975): Lectures on the Philosophy of World History, Cambridge, Cambridge University Press.

Juderías, Julián (1914): La leyenda negra y la verdad histórica, Madrid, Tipografía de la Revista de Archivos.

Kirkpatrick, Susan (1999): “Gender and Modernist Discourse: Emilia Pardo Bazán's Dulce dueño", Modernism and its Margins. Reinscribing Cultural Modernity from Spain and Latin America, Ed. Anthony L. Geist y José B. Monleón, New York, Garland, pp. 117-139.

Krauel, Javier (2013): Imperial Emotions. Cultural responses to Myths of Empire in Fin-de-Siècle Spain, Liverpool UK, Liverpool University Press.

Mazzoni, Cristina (1996): Saint Hysteria: Neurosis, Mysticism, and Gender in European Culture, Ithaca, Cornell University Press.

Menéndez y Pelayo, Marcelino (1920): Historia de las ideas estéticas en España, Vol. 3, Madrid, Imprenta de los Hijos de Tello.

Mignolo, Walter D. (2011): The Darker Side of Western Modernity. Global Futures, Decolonial Options, Durham, Duke University Press.

Nordau, Max (1895): Degeneration, New York, D. Appleton and Company.

Pardo Bazán, Emilia (2006): Cartas de la Condesa en el Diario de la Marina de la Habana, Cuba (1909-1921), Newark, Juan de la Cuesta.

(1994): Crónicas en La Nación de Buenos Aires (1909-1921), Madrid, Pliegos. (1914): Hernán Cortés y sus hazañas, Madrid, Extramuros. 
____ (1901): La España de ayer y la de hoy, Madrid, Administración. (1976): La mujer española y otros artículos feministas, Madrid, Nacional. (1895): Los poetas épicos cristianos, Madrid, Administración. (1964): Obras completas, 3 vols, Madrid, Aguilar. (1886): San Francisco de Asís, París, Librería de Garnier Hermanos.

Pereira-Muro, Carmen (2013): Género, nación y literatura. Emilia Pardo Bazán en la literatura gallega y española, West Lafayette, Purdue University Press.

Roca Barea, María Elvira (2016): Imperiofobia y la leyenda negra, Madrid, Siruela.

Romancero viejo y tradicional (1987): Ed. Manuel Alvar, Ciudad de México, Porrúa.

Ruiz-Ocaña Dueñas, Eduardo (2004): La obra periodística de Emilia Pardo Bazán en La Ilustración Artística de Barcelona (1895-1916), Madrid, Fundación Universitaria Española.

(2015): “La Primera Guerra Mundial contada por Emilia Pardo Bazán en La Ilustración Artística", La Tribuna. Cadernos de Estudios da Casa Museo Emilia Pardo Bazán, 10, pp. 29-50.

Rushdie, Salman (1991): Imaginary Homelands, London, Granta Books.

Sánchez-Llama, Íñigo (2010): “Introducción”, EN Emilia Pardo Bazán, Obra crítica, Madrid, Cátedra, pp. 11-150.

Smith Rousselle, Elizabeth (2014): Gender and Modernity in Spanish Literature 17891920, New York, Palgrave Macmillan.

Unamuno, Miguel de (1958): Obras completas, Vol. 3, Madrid, Afrodisio Aguado.

Valis, Nöel (2002): The Culture of Cursilería. Bad Taste, Kitsch, and Class in Modern Spain. Durham, Duke University Press.

Vélez Cipriano, Iván (2014): Sobre la Leyenda Negra, Madrid, Encuentro. 